\title{
Erratum: Stigmas, Work and Organizations
}

\author{
S. Bruce Thomson and Gina Grandy
}

(C) The Editor(s) (if applicable) and The Author(s) 2018

S.B. Thomson, G. Grandy (eds.), Stigmas, Work and

Organizations, Palgrave Explorations in Workplace Stigma, DOI 10.1057/978-1-137-56476-4

DOI 10.1057/978-1-137-56476-4_13

Table of Contents: Chapter 2, the sequence of the author names was incorrect. The correct sequence is updated as Lisa Watson, Tatiana Levit and Anne Lavack. Chapter 3, the name of the author was incorrect. The correct name is updated as Joy Beatty. Chapter 4, the name of the author was incorrect. The correct name is updated as Rebecca S. Dalgin

Chapter 2: The sequence of the author names was incorrect. The correct sequence is updated as Lisa Watson, Tatiana Levit and Anne Lavack. The correct headers on page $12,14,16,18,20,22,24,26,28,30,32,34$ is updated L. Watson et al.

(C) The Author(s) 2018

E1

S.B. Thomson, G. Grandy (eds.), Stigmas, Work and

Organizations, Palgrave Explorations in Workplace Stigma, DOI 10.1057/978-1-137-56476-4_13 
Chapter 3: The name of the author was incorrect. The correct name is updated as Joy Beatty. The correct headers on page 36, 38, 40, 42, 44, 46, $48,50,52,54$ is updated as J. Beatty. The correct affiliation at the bottom of page 35 is updated as

J. Beatty $(\bowtie)$

University of Michigan-Dearborn, Dearborn, MI, USA

Chapter 4: The name of the author was incorrect. The correct name is updated as Rebecca S. Dalgin. The correct headers on page 56, 58, 60, 62, $64,66,68,70$ is updated as R.S. Dalgin. The correct affiliation at the bottom of page 55 is updated as

R.S. Dalgin, Ph.D. ( $\square)$

University of Scranton, Scranton, PA, USA

The updated online version for these chapters can be found at http://dx.doi.org/10.1057/978-1-137-56476-4_2 http://dx.doi.org/10.1057/978-1-137-56476-4_3 http://dx.doi.org/10.1057/978-1-137-56476-4_4

The updated online version of the book can be found at http://dx.doi.org/10.1057/978-1-137-56476-4 